\title{
La era de la desinformación global: diagnósticos y respuestas
}

\author{
Luis Bouza \\ Universidad Autónoma de Madrid \\ Jorge Tuñón Navarro \\ Universidad Carlos III de Madrid
}

\section{Referencia de este artículo}

Bouza, Luis y Tuñón Navarro, Jorge (2022). La era de la desinformación global: diagnósticos y respuestas. En: adComunica. Revista Científica de Estrategias, Tendencias e Innovación en Comunicación, $\mathrm{n}^{0} 23$. Castellón de la Plana: Departamento de Ciencias de la Comunicación de la Universitat Jaume I, 19-22. DOI: http:// dx.doi.org/10.6035/adcomunica.6441.

En este número especial de adComunica. Revista Científica de Estrategias, Tendencias e Innovación en Comunicación consagrado a la desinformación se presentan cinco artículos de investigación y dos tribunas profesionales que tratan el objeto desde diferentes perspectivas metodológicas, horizontes geográficos, políticos y temporales. El grupo de alto nivel de la UE, en una definición que ha generado un cierto consenso político y académico, ha definido la desinformación como toda «información verificablemente falsa o engañosa que, de manera acumulativa, (a) se crea, presenta y difunde con fines de lucro económico o para engañar intencionalmente al público; y (b) puede causar daño público, con la intención de amenazar a la política democrática y a los procesos de formulación de políticas, así como a bienes públicos como la protección de la salud, el medio ambiente o la seguridad de los ciudadanos de la UE».

Los riesgos asociados a las formas de comunicación que llamamos desinformación no son novedosos ni desconocidos, ni para los profesionales de la comunicación ni para los expertos en estrategia política, económica o militar. Sin embargo, su 
reaparición como preocupación en el debate público actual tiene que ver con la disrupción de las esferas públicas democráticas. Mientras que las esferas públicas estaban fundamentalmente mediadas por actores profesionales y en las mismas participaba la mayor parte de la población, el recorrido comunicativo de los bulos, manipulaciones, sesgos y errores era limitado. Sin embargo, la fragmentación de la esfera pública, la pérdida de autoridad y recursos de los mediadores profesionales y el creciente peso de identidades y creencias en el debate público contribuyen a la duración temporal y a la resiliencia de la desinformación en el debate público.

Precisamente en la importancia de situar la investigación en su contexto actual se ocupa el artículo de David García-Marín, quien analiza las metodologías y los objetos de estudio predominantes en la academia española mediante una revisión sistematizada de todos los artículos sobre desinformación publicados en las revistas españolas indexadas especializadas en comunicación en Scopus y Dialnet. Su exhaustiva revisión cuantitativa demuestra que la investigación sobre las nuevas temáticas en comunicación se sigue realizando con las técnicas y perspectivas vigentes desde hace décadas. En este sentido, el artículo sugiere la necesidad de innovar la producción científica en esta materia.

Este número especial demuestra además la naturaleza transnacional del fenómeno desinformativo y de las estrategias para su combate. En especial, Álvaro Oleart y Luis Bouza estudian la desinformación como un político en disputa en un campo transnacional. Argumentan que los actores de campos como el periodismo o el de la seguridad internacional se ven afectados por una creciente disputa cuyo objetivo es politizar o despolitizar selectivamente las estrategias dominantes para responder a este fenómeno.

Varios de los artículos abordan la cuestión política, profesional y cívica de cómo enfrentarse a la desinformación. Una de las formas que más apoyos tiene en el debate público es la de la verificación o fact-checking, que analizan en sus artículos José Gamir-Ríos y Raquel Tarullo para el caso argentino y Jorge Tuñón y Rocío Sánchez del Vas para el europeo y español. José Gamir-Ríos y Raquel Tarullo, mediante el análisis de contenido de un corpus de 201 desmentidos publicados en 2020 por el verificador Chequeado, proponen una curva de complejidad técnica de la desinformación que muestra el absoluto predominio de los contenidos problemáticos asociados a habilidades digitales muy bajas, bajas o medias. Esto significa que frente a la preocupación creciente ante las desinformaciones creadas de manera profesional o mediante inteligencia artificial resulta importante prestar atención a los riesgos asociados con las «cheapfakes» o manipulaciones toscas. Por su parte, Jorge Tuñón y Rocío Sánchez del Vas se ocupan de una de las limitaciones de la verificación de noticias falsas, a saber, los posibles efectos inversos que refuerzan la credibilidad de aquello que se quiere desmentir. 
La segunda forma de lucha contra la desinformación que se analiza en este número especial tiene que ver con la apuesta por el incremento de la alfabetización mediática. En este sentido, E. Joaquín Suárez-Ruíz y Leonardo González Galli defienden que durante la pandemia de COVID-19 la alfabetización digital demostró ser un enfoque preventivo capaz de ofrecer guías a futuro ante las influencias negativas de los medios digitales en el contexto post-pandemia. El artículo demuestra los efectos de los sesgos cognitivos en la utilización de los medios digitales contemporáneos y analiza el aporte de la metacognición, cuando es comprendida como un componente fundamental de la alfabetización digital, en la identificación de la información errónea y las teorías conspirativas.

Al margen de los trabajos de investigación, este número especial de adComunica consagrado a la desinformación contiene dos tribunas profesionales. La primera desde la perspectiva del propio periodista como creador de contenido y la segunda desde la del verificador (muchas veces también periodista) en calidad de garante de la veracidad de las informaciones.

En ese sentido, primeramente, el Responsable de Innovación en Contenidos de RTVE, David Corral, destaca la lucha que los medios públicos deben hacer frente a la desinformación o las injerencias externas. Apunta acertadamente que en el actual contexto (des) informativo, la labor de estas instituciones debe garantizar la difusión de información y contenidos de entretenimiento y educativos basados en la objetividad, independencia, criterio, neutralidad, imparcialidad y veracidad, en tanto en cuanto, solo de esa forma, podrán cumplir con su propósito de proteger e informar con rigor a las sociedades.

A continuación, Pablo Hernández, coordinador de investigación académica de Maldita.es, presenta el proyecto de esta plataforma para la verificación de bulos. Se trata de un Chatbot diseñado para interactuar con la comunidad del medio en WhatsApp, siendo primer robot que se puso en marcha en español que emplea la conversación con lenguaje natural automatizado con herramientas de Inteligencia Artificial. Lo interesante de la iniciativa reside en que, a través de este chat, los usuarios activan una especie de mecanismo de alerta temprana, advirtiendo de posibles bulos que recorren las conversaciones encriptadas en esa red social, permitiendo el comienzo del proceso para su comprobación.

En definitiva, los siete trabajos que componen este número especial nos invitan a reflexionar acerca de cómo las crisis políticas y de comunicación han desintermediado la esfera pública, empoderado a actores nacionales y extranjeros antidemocráticos, demolido el modelo de negocio de las industrias de la comunicación y afectado sustancialmente los procesos de búsqueda de consenso en las democracias. Es por ello que futuras investigaciones deberán incidir acerca del análisis crítico de los efectos cada vez más profundos de la pandemia en una esfera pública ya perturbada, con especial atención a los debates políticos y académicos 
en curso sobre las estrategias para proteger los procesos de comunicación democrática. En particular, debe profundizarse en el debate acerca de cómo atajar o contrarrestar la desinformación, en calidad de estrategia híbrida, ya que la resolución de dicha discusión, ni que decir tiene, que presumimos que supondrá un impacto decisivo en el reconocimiento de nuevas habilidades profesionales, prácticas o deontológicas. 